\title{
TAHSP:
}

The Internet Joưnal of Allied Health Sciences and Practice

A Peer Reviewed Publication of the College of Health Care Sciences at Nova Southeastern University

Dedicated to allied health professional practice and education

http://ijahsp.nova.edu Vol. 13 No. 1 ISSN 1540-580X

\section{The Research Circle - A Place for Interdisciplinary Learning, Sharing and Networking to Develop Facilitators of Evidence-Based Practice}

\author{
Martina Ingeborg Reinhold, $\mathrm{PhD}^{1}$ \\ Sango Otieno, $\mathrm{PhD}{ }^{2}$
}

1. Assistant Professor, Grand Valley State University, Department of Physician Assistant Studies, Grand Rapids, MI

2. Associate Professor, Grand Valley State University, Department of Statistics, Allendale, MI

United States

CITATION: Reinhold M, Otieno S. The Research Circle- A Place for Interdisciplinary Learning, Sharing and Networking to Develop Facilitators of Evidence-Based Practice. The Internet Journal of Allied Health Sciences and Practice. January 2015. Volume 13 Number 1.

\section{PURPOSE}

Health Professional programs incorporate the principles and methods of clinical research and evidence based medicine (EBM) into their curriculum to encourage evidence based practice in health care. However, many faculty that join health profession programs do so after having worked in clinical practice for some time with limited experience in clinical research and EBM making successful guidance of students difficult for some. This study describes implementation of the Research Circle at Grand Valley State University, where faculty from diverse disciplines such as physician assistant, physical therapy, occupational therapy, speech pathology, radiology, and dietetics came together to share and learn basic concepts in clinical research and EBM. Methods: The Research Circle started in the fall semester of 2013 with monthly meetings and concluded in April of 2014. Meetings consisted of informal presentations on topics relevant to clinical research. A survey was sent to the participants before (pre) and after (post) conclusion of the Research Circle meetings using SurveyMonkey ${ }^{\circledR}$. This survey was designed to assess the general comfort level with clinical research and its perceived importance in teaching as well as clinical practice. Results: A combined 22 faculty participated in at least one meeting of the Research Circle. Nine faculty, who participated in at least $75 \%$ of the Research Circle meetings and completed both the pre as well as post survey, were included in this study. Participation in the Research Circle improved the perceived comfort level of the participants as it relates to research and use of the scientific literature. Furthermore, knowledge of the research process in teaching was valued as more important by faculty after attending the Research Circle. Conclusions: The results described in this preliminary study suggest that implementation of the Research Circle can positively impact faculty perception of and comfort level with clinical research and the scientific literature, establishing a basis from which to develop and improve the skills needed to teach and practice EBM in health care. Notably, the Research Circle has provided an opportunity for faculty from diverse disciplines to come together to learn and discuss, providing a venue to share their research interest and connect.

\section{INTRODUCTION}

When treating patients, healthcare providers often are faced with difficult decisions and considerable uncertainty. To aid the decision making process and ultimately improve patient care, clinical practice guidelines have been established. These guidelines generally encompass a series of recommendations on clinical care supported by the best available evidence in the clinical literature. 1 Yet, a study in the New England Journal of Medicine reported that patients receive only half of the recommended procedures indicated for their care. ${ }^{2} \mathrm{~A}$ variety of barriers have been identified as potential reasons for nonadherence by health care providers. These include lack of awareness, time, and access to printed and electronic resources as 
well as the health care providers' lack of confidence and motivation to change previous practice.,4 Medical knowledge continuously evolves, and the guidelines for best practice are subject to change based on the results of ongoing clinical research. ${ }^{1}$ To adequately address the gap between available clinical recommendations/evidence and actual clinical practice, a new model for medical education and practice has emerged -- evidence based medicine (EBM). EBM is "the conscious, explicit and judicious use of current best evidence in making decisions about the care of the individual patient. The practice of EBM means integrating individual clinical expertise with the best available external clinical evidence from systematic research." 5 EBM de-emphasizes intuition and unsystematic clinical experience and incorporates the clinician's use of current best evidence from well-designed studies and guidelines with his/her expertise and patient values and preferences in clinical decision making., 6,7 The practice of EBM requires new skills of the health care provider, including directed literature searches and the critical evaluation of research studies. ${ }^{8}$ Practitioners will also need to be statistically literate, which includes the ability to confidently evaluate health statistics and draw meaningful conclusions. Recent reports have highlighted that a significant number of health care providers are not able to appropriately evaluate research results or health guidelines, resulting in suboptimal care. ${ }^{9}$ The most effective time point for instruction in EBM has been shown to be for students in health professional programs rather than after graduation and at the workplace. ${ }^{10}$

As a consequence, many health professional programs are incorporating the principles and methods of clinical research and EBM into their curriculum, often as part of a research requirement. 11-13 This necessitates a basic understanding of clinical research and the scientific literature as well as the application of EBM for faculty to efficiently and competently teach and mentor students. However, many faculty that join health profession programs do so after having worked in clinical practice for some time, with little to no experience in clinical research and its methodology. For example, close to $70 \%(68.6 \%)$ of newly hired faculty in physician assistant programs in 2011-2012 were previously employed in clinical practice. ${ }^{14}$ Consequently, successful guidance of students in clinical research as well as incorporation of the principles of EBM into teaching proves difficult for some faculty. ${ }^{15}$ To provide support for faculty as they transition from clinical practice to teaching, the Research Circle was initiated at the College of Health Professions (CHP) at Grand Valley State University (GVSU), focusing on introducing basic concepts of research and EBM. The goal of the Research Circle was to help faculty to become more comfortable with the research process and the scientific literature, establishing a foundation to develop and improve the skills needed to guide students in clinical research and facilitate teaching and practice of EBM. The objective of this study was to provide preliminary results on the ability of the Research Circle to accomplish its goal.

\section{METHODS}

\section{Ethical Review}

This study was reviewed and approved by the GVSU Human Research and Review Committee (HRRC).

\section{Participants}

All faculty members in the CHP at GVSU ( $n=69)$ were invited via e-mail to participate in the Research Circle. Only faculty members who participated in $75 \%$ or more of the Research Circle meetings and completed both surveys (pre and post Research Circle) were included in the study $(n=9)$. Survey responses were matched using the last four digits of the faculty member's university identification number.

\section{Study Design}

In this descriptive longitudinal survey study, a cohort of university professors were surveyed before and after two semesters of implementation of a Research Circle at the CHP at GVSU. The Research Circle was implemented in the fall semester of 2013 and met once a month until April 2014. All faculty were provided with a complimentary copy of "Introduction to Research and Medical Literature for Health Professionals" by Blessing and Forister (2013) at the first meeting of the Research Circle that they attended. The format of the Research Circle included a combination of presentations and discussions and was kept informal to encourage questions and participation from faculty. Topics discussed included ethics in research and human subject protection, survey design, systematic reviews, data analysis, review of the literature-locating relevant evidence, and EBM through a web based course provided free by the United States Cochrane Center (Understanding Evidence based Healthcare: A Foundation for Action: http://us.cochrane.org/understanding-evidence-based-healthcare-foundation-action). For presentations, the educational background and research expertise of faculty and staff within CHP as well as the University was utilized. For example, a faculty member in the Allied Health Department with a Ph.D. in Epidemiology discussed surveys and survey design. Other faculty and staff expertise utilized included a statistician, a librarian and a member of the University Internal Review Board (HRRC at GVSU).

\section{Survey Instrument}

The faculty's perception of and general comfort level with clinical research, use of the scientific literature, and utilization of EBM in teaching and clinical practice was investigated by use of a survey (see Appendix). The survey included 12 questions, with

(c) The Internet Journal of Allied Health Sciences and Practice, 2015 
multiple responses possible on some, as well as questions related to demographics. The authors developed the survey and incorporated suggestions from the GVSU statistical support center as it pertains to organization and clarity. The survey was sent to participants using SurveyMonkey ${ }^{\circledR}$, an online survey tool that allows for anonymity of responses. To determine the repeatability of the questionnaire, a kappa (interpreted according to Altman) statistic and McNemar's test (appropriate when analyzing data from matched pairs of subjects with a dichotomous response) for symmetry were computed for questions. ${ }^{15}$ Because of the small sample size, the responses to the questions were made dichotomous.

\section{DATA ANALYSIS}

Due to the small sample size, the data is summarized using only descriptive statistics. Responses of participants in the pre and post survey were analyzed as a group, and although the sample size is small, the trends observed in this preliminary study are consistent.

\section{RESULTS}

Of the 69 faculty at the College of Health Professions, 22 faculty participated in at least one meeting of the Research Circle $(32 \%)$, spanning all departments of the College (Allied Health Sciences, Physical Therapy, Public Health, Occupational Therapy, Physician Assistant Studies, Speech Pathology, Therapeutic Recreation, and Radiologic and Imaging Sciences). Of these 22 faculty, 9 participated in $75 \%$ or more of the meetings and completed both the pre and post survey and were included in this study (40\%). Four faculty completed only the "pre" survey and one faculty completed only the "post" survey and were not included in this study. The remaining eight faculty members participated in at least one of the Research Circle meeting and did not complete a survey.

Of the study participants, a significant number had joint GVSU in the past 2 years $(66 \%)$ and indicated that this was their first academic employment (66\%; Table 1). More than half of the faculty (55\%) joined the College of Health professions at GVSU directly form a position in clinical practice (Table 1).

Table 1. Self-Reported Data from Survey

\begin{tabular}{|cc|}
\hline \multicolumn{1}{|c|}{ CHARACTERISTIC } & \% (No.) ${ }^{\text {a }}$ \\
\hline Length of Time at GVSU & $66 \%(6)$ \\
\hline $\mathbf{0 - 2}$ years & $22 \%(2)$ \\
\hline 2-5 years & $11 \%(1)$ \\
\hline $\mathbf{5 - 1 0}$ Years & $66 \%(6)$ \\
\hline First Employment at an Academic Institution & $33 \%(3)$ \\
\hline Yes & $55 \%(5)$ \\
\hline No & $11 \%(1)$ \\
\hline Type of employment prior to coming to GVSU & $11 \%(1)$ \\
\hline Clinical & $11 \%(1)$ \\
\hline Business & \\
\hline Research & \\
\hline Education & a Percentages based on denominator of 9 participants included in study.
\end{tabular}

\section{Influence of the Research Circle on faculty's comfort level with research}

Respondents perceived comfort level with research as well as the possibility of mentoring a student research group consistently improved after participation in the Research Circle (Table 2). For example, the number of faculty that were somewhat comfortable/ comfortable / very comfortable with the concept of clinical research doubled (from $33 \%$ to $66 \%$ ) after participation. At the same time, fewer faculty (from $33 \%$ to $11 \%$ ) felt intimidated /not very comfortable with the concept of research and faculty were twice "as comfortable" (from $22 \%$ to $44 \%$ ) with the idea of mentoring a student research group (Table 2). 
Table 2. Faculty Comfort with Research Prior and After Participation in the Research Circle

\begin{tabular}{|lll|}
\hline & \multicolumn{2}{l|}{$\%$ (No.) } \\
\hline & Pre & Post \\
\hline Comfort with concept of & \\
\hline Research & \\
\hline Intimidated & $11 \%(1)$ & 0 \\
\hline Not very comfortable & $22 \%(2)$ & $11 \%(1)$ \\
\hline Somewhat comfortable & $22 \%(2)$ & $44 \%(4)$ \\
\hline Comfortable & $33 \%(3)$ & $33 \%(3)$ \\
\hline Very Comfortable & $11 \%(1)$ & $11 \%(1)$ \\
\hline & & \\
\hline Clinical Research & & 0 \\
\hline Intimidated & $11 \%(1)$ & $33 \%(3)$ \\
\hline Not very comfortable & $55 \%(5)$ & $55 \%(5)$ \\
\hline Somewhat comfortable & $22 \%(2)$ & $11 \%(1)$ \\
\hline Comfortable & $11 \%(1)$ & \\
\hline & & $22 \%(2)$ \\
\hline Mentor student research group & $33 \%(3)$ \\
\hline Not very comfortable & $44 \%(4)$ \\
\hline Somewhat comfortable & $33 \%(3)$ & $44 \%(4)$ \\
\hline Comfortable & $22 \%(2)$ & \\
\hline
\end{tabular}

a Percentages based on denominator of 9 participants included in study.

\section{Importance of Understanding Research Process as Teacher and Clinician}

Following attendance of the Research Circle, professors in the College of Health Profession reported an increase in rating knowledge of the research process as "very important" in order to be an effective teacher (from $44 \%$ to $77 \%$; Table 3 ). Participation in the Research Circle had little impact on the perceived importance of knowledge of research concepts in order to be effective in clinical practice (very important: from $57 \%$ to $43 \%$ ). Furthermore, fewer faculty considered knowledge of the research process to be "very important" for clinical practice as compared to teaching ( $43 \%$ vs $77 \%$, respectively; Table 3 ).

Table 3. Importance of Faculty to Be Knowledgeable in Research Process as It Relates to Teaching and Clinical Practice.

\begin{tabular}{|c|c|c|}
\hline & \multicolumn{2}{|c|}{$\%$ (No.) ${ }^{a}$} \\
\hline & Pre & Post \\
\hline \multicolumn{3}{|c|}{ Knowledge of research process to be an effective } \\
\hline \multicolumn{3}{|c|}{ Teacher } \\
\hline Somewhat Important & $11 \%(1)$ & $11 \%(1)$ \\
\hline Important & $44 \%(4)$ & $11 \%(1)$ \\
\hline Very Important & $44 \%(4)$ & $77 \%(7)$ \\
\hline \multicolumn{3}{|l|}{ Clinician } \\
\hline Somewhat Important & $43 \%(3)$ & $14 \%(1)$ \\
\hline Important & 0 & $28 \%(2)$ \\
\hline Very Important & $57 \%(4)$ & $43 \%(3)$ \\
\hline I don't know & 0 & $14 \%(1)$ \\
\hline
\end{tabular}

a Percentages not all based on denominator of 9 because of missing responses to some survey items.

\section{Importance of Utilizing Research Literature as Teacher and Clinician}

Participation in the Research Circle doubled the number of faculty that "often" utilize the scientific literature in their teaching and clinical practice (from $33 \%$ to $66 \%$ for both; Table 4), with all of the participants indicating the use of scientific literature for their teaching as "sometimes" or "often" ( $33 \%$ and $66 \%$, respectively) after participation. In contrast, $33 \%$ of the participants specified that they "never" or "rarely" use the scientific literature in clinical practice (Table 4). As it pertains to utilizing the scientific literature to verify clinical guidelines prior to lectures, twice as many faculty indicated that they do so "often" (33\% vs $66 \%$ ) after 
taking part in the Research Circle. It should be noted that the number of participants that "never/rarely" verify clinical guidelines prior to lectures did not change (33\%) following participation in the Research Circle (Table 4).

Table 4. Use of the Scientific Literature as a Resource by Faculty in Teaching and Clinical Practice.

\begin{tabular}{|c|c|c|}
\hline & & $(\text { No. })^{a}$ \\
\hline & Pre & Post \\
\hline Use of scientific liter & & \\
\hline Teaching & & \\
\hline Rarely & $11 \%(1)$ & 0 \\
\hline Sometimes & $44 \%(4)$ & $33 \%(3)$ \\
\hline Often & $33 \%(3)$ & $66 \%(6)$ \\
\hline Always & $11 \%(1)$ & 0 \\
\hline Clinical Practice & & \\
\hline Never & $11 \%(1)$ & $11 \%(1)$ \\
\hline Rarely & $22 \%(2)$ & $22 \%(2)$ \\
\hline Sometimes & $33 \%(3)$ & 0 \\
\hline Often & $33 \%(3)$ & $66 \%(6)$ \\
\hline Verifying Clinical Gui & & \\
\hline Never & $11 \%(1)$ & $11 \%(1)$ \\
\hline Rarely & $22 \%(2)$ & $22 \%(2)$ \\
\hline Sometimes & $33 \%(3)$ & 0 \\
\hline Often & $33 \%(3)$ & $66 \%(6)$ \\
\hline
\end{tabular}

When asked what resources are utilized to search for answers, faculty specified the use of Google (32\%), textbook (37 \%) or talk to colleague $(26 \%)$ as major sources to find answers (Table 5).

Table 5. Resources Utilized to Answer Questions Related to Teaching or Clinical Practice.

\begin{tabular}{|lc|}
\hline & $\%(\text { No. })^{\text {a }}$ \\
\hline Resources utilized & $32 \%(6)$ \\
\hline Google & $5 \%(1)$ \\
\hline Newspaper & $37 \%(7)$ \\
\hline Textbook & $26 \%(5)$ \\
\hline Talk to colleague & \\
\hline
\end{tabular}

a Percentages based on denominator of 15 (total number of responses) as response to more than one item was permitted.

\section{Reliability of Survey}

8 participants were used in order to assess the repeatability of the survey. These participants completed all questions in both the pre and post survey, with seven or eight months between the two measurements. Results in Table 6 indicate that the survey was test-retest reliable (all $p$-values > 0.05). (Note Kappa Agreement: < 0 : Less than chance agreement, 0.01 to 0.20: Slight agreement, 0.21 to 0.40: Fair agreement, 0.41 to 0.60: Moderate agreement, 0.61 to 0.80: Substantial agreement, 0.81 to 0.99 : Almost perfect agreement). ${ }^{16}$ 
Table 6. Statistical Computation Analyzing the Reliability of the Survey

\begin{tabular}{|c|c|c|c|c|}
\hline \multicolumn{2}{|l|}{ Question } & $\begin{array}{l}\text { McNemar's test } \\
\text { for symmetry } \\
\text { Asymptotic } \\
\text { P-value }\end{array}$ & Kappa & $\begin{array}{c}\text { Kappa } \\
\text { Agreement }\end{array}$ \\
\hline \multicolumn{2}{|c|}{$\begin{array}{c}\text { Before your lecture do you verify that the clinical guidelines } \\
\text { you are presenting are up to date? } \\
\text { [Often/Always(Yes)/ Rarely/Never (No)] }\end{array}$} & $\begin{array}{c}\text { There are no } \\
\text { discordant pairs }\end{array}$ & - & - \\
\hline \multicolumn{2}{|c|}{$\begin{array}{c}\text { Please rate your proficiency with regard to interpreting } \\
\text { statistical results } \\
\text { [ Proficient/Very (Yes)/ Not/Somewhat (No)] }\end{array}$} & 1.0000 & -0.1429 & $\begin{array}{l}\text { Less than Chance } \\
\text { agreement }\end{array}$ \\
\hline \multirow{2}{*}{$\begin{array}{c}\text { Please rate your comfort level with } \\
\text { [Somewhat Comfortable/ Comfortable/Very } \\
\text { Comfortable (Yes)/ Intimidated/Not Very } \\
\text { Comfortable (No)] }\end{array}$} & $\begin{array}{l}\text { The concepts } \\
\text { of research? }\end{array}$ & 0.3173 & 0.6000 & $\begin{array}{l}\text { Moderate } \\
\text { agreement }\end{array}$ \\
\hline & $\begin{array}{l}\text { Clinical } \\
\text { research in } \\
\text { particular? }\end{array}$ & 0.5637 & 0.2500 & Fair agreement \\
\hline \multirow{2}{*}{$\begin{array}{l}\text { How often do you search out the primary } \\
\text { literature (such as research articles or } \\
\text { reviews) to find an answer to a question you } \\
\text { have as it relates to your } \\
\text { [Sometimes/ Often/ Always (Yes)/ Never/Rarely } \\
\text { (No)] }\end{array}$} & Teaching? & $\begin{array}{c}\text { There are no } \\
\text { discordant pairs }\end{array}$ & - & - \\
\hline & $\begin{array}{c}\text { Clinical } \\
\text { practice? }\end{array}$ & 0.3173 & 0.7143 & $\begin{array}{l}\text { Substantial } \\
\text { agreement }\end{array}$ \\
\hline \multirow{2}{*}{$\begin{array}{l}\text { Please indicate the importance of being } \\
\text { knowledgeable about the research process } \\
\text { in order to be a good } \\
\text { [Important/ Very Important (Yes)/ Somewhat } \\
\text { Important/ Not Important (No)] }\end{array}$} & $\begin{array}{l}\text { Teacher in the } \\
\text { health } \\
\text { sciences? }\end{array}$ & $\begin{array}{c}\text { There are no } \\
\text { discordant pairs }\end{array}$ & - & - \\
\hline & Clinician? & 0.1573 & 0.3846 & Fair agreement \\
\hline
\end{tabular}

\section{DISCUSSION}

This study provides preliminary results suggesting that the implementation of the Research Circle can improve the comfort level of faculty as it relates to clinical research and the utilization of the scientific literature. Participants largely reported positive changes in how they view the importance of clinical research as well as the use of the scientific literature in teaching and clinical practice. A previous study by Pravikoff et al reported a "lack of value for research" and "gaps in their experience with research appraisal" as prominent barriers to utilizing research in practice and teaching, underscoring the significance of increasing awareness of and improving the attitude towards research for both provider as well as educator in the health care professions. ${ }^{17}$ More than half of the study participants joined the College of Health Profession directly form a position in clinical practice, highlighting the challenges health profession programs face as it pertains to faculty experience with academia as a whole and research in particular. Although very talented as health care providers, many of these faculty have very limited experience in teaching and scholarly activities. The challenges associated with this career transition have been recognized by many health profession programs, and specific faculty development initiatives have been established to build a bridge from clinical practice to academic environment. ${ }^{18}$ Topics addressed in these workshops, seminars, or meetings include academic culture and responsibilities and preparation for the academic environment, as well as training in teaching skills. At GVSU, the Faculty Teaching and Learning Center (FTLC) provides support to new faculty in the form of faculty mentoring communities and facultyto-faculty mentoring programs. ${ }^{19}$ These faculty development and support programs are very important for the developing professor but are more focused on teaching skills and support with less help provided as it relates to scholarly activities and the practice of EBM. Participation in the Research Circle provided research development and scholarly opportunities to participants that they might not have had otherwise.

An important element of the Research Circle was the collaborative nature of the meetings. Topics were not presented in lecture format but rather as points of discussion. This allowed the faculty, regardless of his or her level of expertise, to participate either by asking questions or by providing information and promoting the discussion (personal observation). Participants had an 
opportunity in a non-threatening environment to listen, ask, and learn about aspects of research and its application. Importantly, as faculty from different disciplines participated in the Research Circle, new contacts were formed, allowing for future collaboration on research projects. A review by Smesney et al identified a lack of mentoring as a common barrier to pursuing scholarship by junior faculty in the health sciences. ${ }^{20}$ Although the Research Circle was not designed as a mentoring program, it did provide the opportunity for junior faculty to interact with and learn from more senior faculty. While some senior faculty participated in the study (see Table 1), most of the senior faculty took part in the Research Circle as presenters or participated in select meetings and did not complete the survey (personal observation).

Although worrisome, the observation that a third of the study participants did not utilize the scientific literature to verify clinical guidelines is not unique to this study. Scollin found that "new sources of information, new research and new evidence for practice were used infrequently, if at all."21 Unfamiliarity with the use of evidence-based practice and a lack of knowledge on how to efficiently utilize the scientific literature to answer clinical questions frequently results in the utilization of one of the lowest forms of evidence to find answers to clinical problems: person-to-person communication. ${ }^{21}$ Even though the Research Circle did not necessarily improve the proficiency of faculty in research methods, such as interpretation of statistical results (data not shown), this study offers preliminary evidence that participation lessened the discomfort with the concept of research and use of the scientific literature and strengthened the recognition that science and research are important for the health care professions.

The observation that participants regard knowledge of the research process as more important in their role as a teacher rather than as a clinician suggests a gap between what is being taught in the classroom and what is actually practiced. Lack of time, access to resources, or the availability of colleagues to confer with could be possible explanations for this behavior. Experiences like the Research Circle have the potential to provide valuable opportunities for faculty to close that gap by learning about and then actively incorporating evidence based practice into their teaching and role as clinician.

A primary weakness of this study was the small sample size, which allowed only for a descriptive examination of the results. Finding a time that was workable for most faculty interested in attending proved to be a major obstacle, and only a relatively small number of faculty was able to consistently participate in the Research Circle. For some faculty, teaching obligations, faculty meetings or committee responsibilities interfered with attendance at all or some of the meetings. Alternatives to meeting times need to be identified that will work for the majority of interested faculty, such as late afternoon or evening. Another exciting option would be to utilize on-line meeting formats. Possibilities can range from on-line discussion groups to utilizing Skype ${ }^{\mathrm{TM}}$ or $00 \mathrm{~V}_{00}{ }^{\mathrm{TM}}$ to make late afternoon or evening meetings accessible to those faculty that are available but cannot be at the designated meeting location. Using on-line formats will require adjustments from the traditional face-to-face sessions, but with increased exposure to hybrid and on-line classes, faculty are becoming more familiar with the use of on-line technology as a means to share information. Future studies will focus on finding workable meeting times and/or formats to allow for all interested faculty to participate and will include a post-Research Circle evaluation to determine the participants' perspectives as to the program's effectiveness.

The results of this study contribute preliminary data indicating that implementation of the Research Circle had a positive impact on the faculty in the CHP at GVSU. The small sample size limited data analysis to descriptive statistics, but the trends observed in this preliminary study are consistent. Participation in the Research Circle presented participants with the opportunity to become more familiar and comfortable with concepts of clinical research and EBM, providing the foundation required for faculty to invest time and resources in becoming more proficient and skilled at both. Increased competency with the concepts and use of EBM will allow integrating the practice more readily into the curriculum. This will not only instill the knowledge and skills of EBM in students, but will also help current and future health professionals to value research and pursue scholarly activities.

\section{REFERENCES}

1. Weisz G, Cambrosio A, Keating P, Knaapen L, Schlich T, Tournay VJ. The emergence of clinical practice guidelines. Milbank Q. 2007;85(4):691-727.[PMID: 18070334]

2. McGlynn EA, Asch SM, Adams J, Keesey J, Hicks J, DeCristofaro A, Kerr EA. The quality of health care delivered to adults in the Unites States. N Engl J Med. 2003;348(26):2635-45. [PMID: 12826639]

3. Cabana MD, Rand CS, Powe NR, Wu AW, Wilson MH, Abboud PA, Rubin HR. Why don't physicians follow clinical practice guidelines? A framework for improvement. JAMA. 1999;282(15):1458-65. [PMID: 10535437]

4. Estabrooks CA. Will evidence-based nursing practice make practice perfect? Can J Nurs Res 1998;30(1):15-36. [PMID: 9726180]

5. Sackett DL, Rosenberg WM, Gray JA, Haynes RB, Richardson WS. Evidence based medicine:what it is and what it isn't. BMJ. 1996;312(7023):71-2.

6. Guyatt GH, Naylor D, Richardson WS, Green L, Haynes RB, Wilson MC, Cook DJ, Jaeschke RZ. What is the best evidence for making clinical decisions? JAMA. 2000;284(24):3127-8. [PMID: 11135774]

(c) The Internet Journal of Allied Health Sciences and Practice, 2015 
7. Melnyk B, Fineout- Overhaolt E. Evidence based practice in nursing and healthcare: A guide to best practice. Philadelphia: Lippincott, Williams \& Wilkins; 2005:39-70.

8. Guyatt G, Cook D, Haynes B. Evidence based medicine has come a long way: The second decade will be as exciting as the first. BMJ. 2004;329(7473):990-1. [PMID: 15514320]

9. Wegwarth O, Schwartz LM, Woloshin S, Gaissmaier W, Gigerenzer G. Do physicians understand cancer screening statistics? A national survey of primary care physician in the United States. Ann Intern Med. 2012;156(5):340-9. [PMID: 22393129]

10. Norman GR, Shannon SI. Effectiveness of instruction in critical appraisal (evidence-based medicine) skills: a critical appraisal. Can Med Assoc J. 1998;158(2):177-81. [PMID: 9469138]

11. Forrest JL, Miller SA. Intergrating evidence-based decision making into allied health curricula. J Allied Health. 2001;30(4):215-22. [PMID: 11828582]

12. Tagney J, Haines C. Using evidence-based practice to address gaps in nursing knowledge. Br J Nurs. 2009;18(8):484-9. [PMID: 19377394]

13. Emerson RJ, Records K. Today's challenge, tomorrow's excellence: the practice of evidence-based education. J Nurs Educ. 2008;47(8):359-70. [PMID: 18751650]

14. Physician Assistant Education Association, 28th Annual Report on Physician Assistant Educational Programs in the United States, 2011-2012. http://www.paeaonline.org/index.php?ht=a/GetDocumentAction/i/156969. Published May 2013. Accessed January 5, 2015.

15. Altman DG. Practical Statistics for medical research. London, UK: Chapman \& Hall/CRC. 2001.

16. Viera AJ, Garrett JM. Understanding Interobserver Agreement: The Kappa Statistic. Family Medicine. 2005;37(5):360-3.

17. Pravikoff DS, Tanner A, Pierce ST. Readiness of U.S. nurses for evidence-based practice. American Journal of Nursing. 2005;105:40-51. [PMID: 16138038]

18. Hicks JL, Hendricson WD, Partida MN, Rugh JD, Littlefield JH, Jacks ME. Career transition and dental school faculty development program. Tex Dent J. 2013;130(11):1115-22. [PMID: 24400416]

19. Pew Faculty Teaching and Learning Center, Grand Valley State University. http://www.gvsu.edu/ftlc/. Accessed December 11, 2014.

20. Smesney AL, Williams JS, Brazeau GA, Weber RJ, Matthews HW, Das SK. Barriers to scholarship in dentistry, medicine, nursing and pharmacy practice faculty. Am J Pharm Educ. 2007;71(5):1. [PMID: 17998988]

21. Scollin P. A study of factors related to the use of online resources by nurse educators. Comput Nurs 2001;19(6):249-56. [PMID: 11764716]

\section{Research Circle}




\section{Faculty Survey}

1. Please rate your comfort level with the concepts of research?

a. Intimidated

b. Not very comfortable

c. Somewhat comfortable

d. Comfortable

e. Very comfortable

2. Please rate your comfort level with clinical research in particular?

a. Intimidated

b. Not very comfortable

c. Somewhat comfortable

d. Comfortable

e. Very comfortable

3. How often do you search out the primary literature (such as research articles or reviews) to find an answer to a question you have as it relates to your teaching?

a. Never

b. Rarely

c. Sometimes

d. Often

e. Always

4. How often do you search out the primary literature (such as research articles or reviews) to find an answer to a question you have as it relates to your clinical practice?

a. Never

b. Rarely

c. Sometimes

d. Often

e. Always

5. What is the main reason that you do not utilize the primary literature as a means to find answers to your questions? You may mark as many answers as apply.

a. No time

b. Difficulty identifying the appropriate article

c. Difficulty locating the appropriate article

d. Difficulty reading the appropriate article

e. Difficulty evaluating the findings in the article

f. Other (please specify):

6. What sources do you utilize to find answers to your questions? Please check ALL that apply.

a. Google

b. Newspaper

c. Textbook

d. Talk to colleague

e. Don't worry about finding the answer

f. Not applicable

7. Before your lecture do you verify that the clinical guidelines you are presenting are up to date?

a. Never

b. Rarely

c. Sometimes

d. Often

e. Always 
8. When you read a research article, which section do you have the most trouble understanding? Please check ALL that apply.

a. Purpose of study

b. Study design

c. Identification of appropriate study population

d. Statistics

e. Application of results of study

f. Not applicable

9. Please rate your proficiency with regard to interpreting statistical results

a. Not proficient

b. Somewhat proficient

c. Proficient

d. Very proficient

10. Please indicate your comfort level to mentor one of the student research groups in your department?

a. Not comfortable

b. Somewhat comfortable

c. Comfortable

d. I don't know

11. Please indicate the importance of being knowledgeable about research process in order to be a good teacher in the health sciences?

a. Not important

b. Somewhat important

c. Important

d. Very important

e. I don't know

12. Please indicate the importance of being knowledgeable about the research process in order to be a good clinician?

a. Not important

b. Somewhat important

c. Important

d. Very important

e. I don't know

13. How long have you been at GVSU?

a. $0-2$ years

b. $2-5$ years

c. $5-10$ years

d. $>10$ years

14. Is this your first employment at an academic institution?

a. Yes

b. No

15. What type of employment did you have prior to coming to GVSU?

a. Clinical

b. Business

c. Research

d. Did not work

e. Other (please specify) 